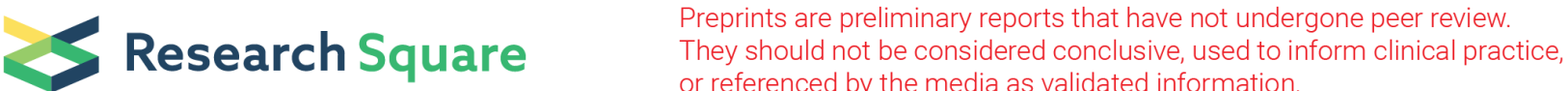 \\ An AIDS Patient With Recurrent Multiple Skin Crusted Ulcerations
}

\section{Yu Wang}

The First Affiliated Hospital of China Medical University of Infectious Diseases, Shenyang, China

\section{Ying Wen ( $\nabla$ Wenying666466@163.com )}

Department of Infectious Diseases, The First Affiliated Hospital of China Medical University, 155 Nanjing North Street, Shenyang 110001, Liaoning Province, China

\section{Case report}

Keywords: malignant syphilis, acquired immune deficiency syndrome, ulceration『case report

Posted Date: August 6th, 2020

DOl: https://doi.org/10.21203/rs.3.rs-51816/v1

License: (1) This work is licensed under a Creative Commons Attribution 4.0 International License.

Read Full License

Version of Record: A version of this preprint was published at AIDS Research and Human Retroviruses on January 1st, 2021. See the published version at https://doi.org/10.1089/aid.2020.0212. 


\section{Abstract}

Background:Malignant syphilis is considered a rare disease, more commonly affecting individuals with poor immunity. We report a case of acquired immune deficiency syndrome with Repeated crusted ulcerations. Our report shows the typical skin lesions of malignant syphilis and a reinfection with the same rashes.

Case presentation:A 22-year-old homosexual male was admitted to hospital for fever and ulcerations with overlying brown-black rupioid crusts. Then he was confirmed human immunodeficiency virus infection. Malignant syphilis was diagnosed by positive markers and biopsy pathology. After application of benzathine penicillin for 3 weeks, the symptoms improved and rapid plasma regain (RPR) decreased from 1:64 to 1:4 in 8 months. But the patient appeared with rashes that was accurately the same with rashes before 13 months later冈and RPR rose to 1:128, that was likely to be re-infection after frequent sexual activity. And he responded well to doxycycline treatment.

Conclusion: Malignant syphilis is a rare form of secondary syphilis, but tends to occur in acquired immune deficiency syndrome patients because of poor immunity. Although the clinical manifestations of malignant syphilis are severe, the response to the therapy of penicillin and doxycycline are excellent, even with repeated infection.

\section{Background}

Malignant syphilis is an unusual ulcerative variation of secondary syphilis $\bigotimes$ that is normally found in immunosuppressed patients. These ultimately form ulcers with raised edges and central necrosis and may be followed by rupioid crusts[1].

This study describes the case report of a 22-year-old man who discoversacquired immune deficiency syndrome(AIDS)and syphilis at the same time for presenting of fever and skin disseminatedbrown-black rupioid crustscompatible with malignant syphilis.

\section{Case Report}

A 22-year-old homosexual male presented with fever, maculopapules and blisters on his face, trunk, and extremities just after removing the nasal prosthesis 40 days before admitted into hospital. He had been diagnosed as chickenpox at an early stage, without special treatment, and the rash has not subsided. He had been treated with levofloxacin for a week,the temperature gradually decreased to normal, but the rash did not improve 20 days before admission. When the blisters broke, the skin ulcerated and then scabbed with overlying brown-black rupioid crusts within 20 days. When he was admitted to hospital, there were multiple skin crusted ulcerations on the trunk (Fig.1a) and extremities (Fig.1b). There was a small ulcer with yellow discharge in the perineum, swelling of bilateral Subaxillary lymph nodes. He had a history of men who have sex with men (MSM) for 5 years. 
The examinations showed white blood cell (WBC) $11.98 \times 10^{9} /$ LØneutrophils $9.82 \times 10^{9} / \mathrm{L}$, hemoglobin $(\mathrm{Hb})$ $130 \mathrm{~g} / \mathrm{L}$, C-reactive protein (CRP) $152 \mathrm{mg} / \mathrm{dL}$, serum immunoglobulins and anti-neutrophil cytoplasmic antibodies (ANCA) were normal, cultures of fungi, bacteria were negative. He was confirmed human immunodeficiency virus(HIV) infection and his $C D 4^{+} T$ cell counts were $117 / \mu \mathrm{L}, \mathrm{HIVRNA}$ $4.22 \times 10^{5} \mathrm{copies} / \mathrm{mL}$. The biopsy pathology of right forearm lesion (Fig. $1 \mathrm{c}$ ) showed an ulcer, dense inflammatory cells infiltrated in the dermis, including neutrophil, lymphocytes and histocytes, there was deep perivascular infiltration of lymphocytes and plasma cells. AIDS was confirmed. Malignant secondary syphilis was diagnosed according to the biopsy pathology, positive serum syphilis enzyme immunoassay (EIA)screening and high serum rapid plasma regain (RPR) testtiter (1:64). After application of benzathine penicillin for 3 weeks, the rashes were in complete remission (Fig.1d). Then the patient began with highly active antiretroviral therapy (HAART) therapy (zidovudine, lamivudine, nevirapine). But zidovudine was changed to tenofovir dipivoxil for severe anemia $(\mathrm{Hb} 54 \mathrm{~g} / \mathrm{L})$.

In the follow-up, the RPR titer decreased (1:4) 8 months later, HIV-RNA was negative and CD4 ${ }^{+} \mathrm{T}$ cells were significantly increased $(522 / \mu \mathrm{L})$. But 13 months later, the patient appeared with fever and rashes again. The rashes was also multiple skin crusted Ulceration, accurately the same with rashes before but more intensive. The RPR rose to $1: 64$, and then $1: 128$ in 2 weeks, WBC was $8.59 \times 10^{9} / \mathrm{L}$, CRP was $99.5 \mathrm{mg} / \mathrm{dL}, \mathrm{CD} 4^{+} \mathrm{T}$ cells were $657 / \mu \mathrm{L}$. It was likely to be re-infection of syphilis after frequent sexual activity. Since penicillin skin test was positive, doxycycline was applied for 4 weeks, andRPR decreased to $1: 4$, rashes disappeared again.

\section{Discussion}

Malignant syphilis is an uncommon form of destructive secondary syphilis. Amulticentric retrospective study found that $1.33 \%$ (151/11368) of HIV-infected individualsin Germanyhad syphilis, of which $7.3 \%$ (11/151) were malignant syphilis[2].HIV-infected patients were 60 times more likely to present with malignant syphilis compared with general population[3].

The clinical manifestationsof syphilis might be altered withimpairment of both humoral and cellmediated immunity by HIV[4], which may limit the host's defenses against treponema pallidum. The progressive, destructive course of malignant syphilis may be due to an immunocompromised condition of the host, a virulent strain, or even an inappropriate immune response $[5,6]$.

Malignant syphilis is characterized by occlusion of the blood vessels with resultant fibrinoid necrosis at the dermal-subcutaneous junction[7]. The skin lesions of malignant syphilis are just like this patient, start as papules and evolve into pustules, then the lesion centre undergoesnecrosis, resulting in ulcers and scabbed with overlying rupioid crusts.

In this patient, the diagnosis of malignant syphilis was confirmed by the positive RPR/EIA titer, characteristic clinical nodular lesions, a plasma cell-rich inflammatory infiltrate on pathology, and good response to benzathine penicillin. However, a year later, the patient developed fever again, the appearance 
of the rash was the same as before, and the RPR increased again.ls it a relapse or reinfection?Since the RPR of the patients had been at a low level during the nearly 1-year follow-up, and the RPR rose to 1:64, and then 1:128 in 2 weeks, it was considered that the patients had a high possibility of "syphilis reinfection", for the patient admitted to having frequent sex in recent months.Fortunately, the patient responded well to doxycycline treatment. Despite its name, malignant syphilis is usually treated well after accurate diagnosis and regular treatment[8].

\section{Conclusion}

Malignant syphilis is a rare form of secondary syphilis, but tends to occur in AIDS patients because of poor immunity. Although the clinical manifestations of malignant syphilis are severe, the response to the therapy of both penicillin and doxycycline are excellent.

\section{Declarations}

\section{Ethics approval and consent of participate}

Informed consent was obtained in this case and protocols were approved by the Human ethics committee of The First Affiliated Hospital of China Medical University.

\section{Consent for publication}

The patient provided written, informed consent for publication of the details of this case.

\section{Availability of data and material}

All data generated or analyzed in this case report are included in this published article.

\section{Competing interests}

The authors declare that they have no competing interests.

\section{Funding}

This work was supported by the ShenYang Science and Technology Bureau(18-014-4-30 to Wen Ying ).

\section{Authors' contributions}

All authors analyzed and interpreted the patient data. $W Y^{1}$ and $W Y^{2}$ treated the patient, made the clinical diagnosis, wrote and revised the manuscript.All authors have read and approved the final manuscript. (WY ${ }^{1}$ is Wang Yu and $W Y^{2}$ is WenYing )

\section{Acknowledgements}


We thank Xiao Ting (Dermatology of the First AffiliatedHospital of China Medical University), Zhou Ying (Infectious disease of the First Affiliated Hospital of China Medical University) for their professional assistance. We also thank the patient for agreeing to submit his case.

\section{Authors' information}

Affiliations

The First Affiliated Hospital of China Medical University of Infectious Diseases, Shenyang, China Wang Yu凶Wen Ying

Corresponding author

Correspondence to Wen Ying.

\section{Reference}

1. Cid PM, Cudos ES, Zamora Vargas FX, Merino MJ, Pinto PH: Pathologically confirmed malignant syphilis using immunohistochemical staining: report of 3 cases and review of the literature. Sexually transmitted diseases 2014, 41(2):94-97.

2. Schofer H, Imhof M, Thoma-Greber E, Brockmeyer NH, Hartmann M, Gerken G, Pees HW, Rasokat H, Hartmann H, Sadri I et al: Active syphilis in HIV infection: a multicentre retrospective survey. The German AIDS Study Group (GASG). Genitourinary medicine 1996, 72(3):176-181.

3. Tucker JD, Shah S, Jarell AD, Tsai KY, Zembowicz A, Kroshinsky D: Lues maligna in early HIV infection case report and review of the literature. Sexually transmitted diseases 2009, 36(8):512-514.

4. Bowen DL, Lane HC, Fauci AS: Immunopathogenesis of the acquired immunodeficiency syndrome. Annals of internal medicine 1985, 103(5):704-709.

5. Kumar B, Muralidhar S, Das A: Malignant syphilis: an immunological puzzle. International journal of STD \& AIDS 1998, 9(2):114-116.

6. Bahmer FA, Anton-Lamprecht L: Ultrastructural features of malignant syphilis and demonstration of Treponema pallidum. International journal of dermatology 1983, 22(3):165-170.

7. Gevorgyan O, Owen BD, Balavenkataraman A, Weinstein MR: A nodular-ulcerative form of secondary syphilis in AIDS. Proceedings 2017, 30(1):80-82.

8. Stoner BP: Current controversies in the management of adult syphilis. Clinical infectious diseases : an official publication of the Infectious Diseases Society of America 2007, 44 Suppl 3:S130-146. 


\section{Figures}

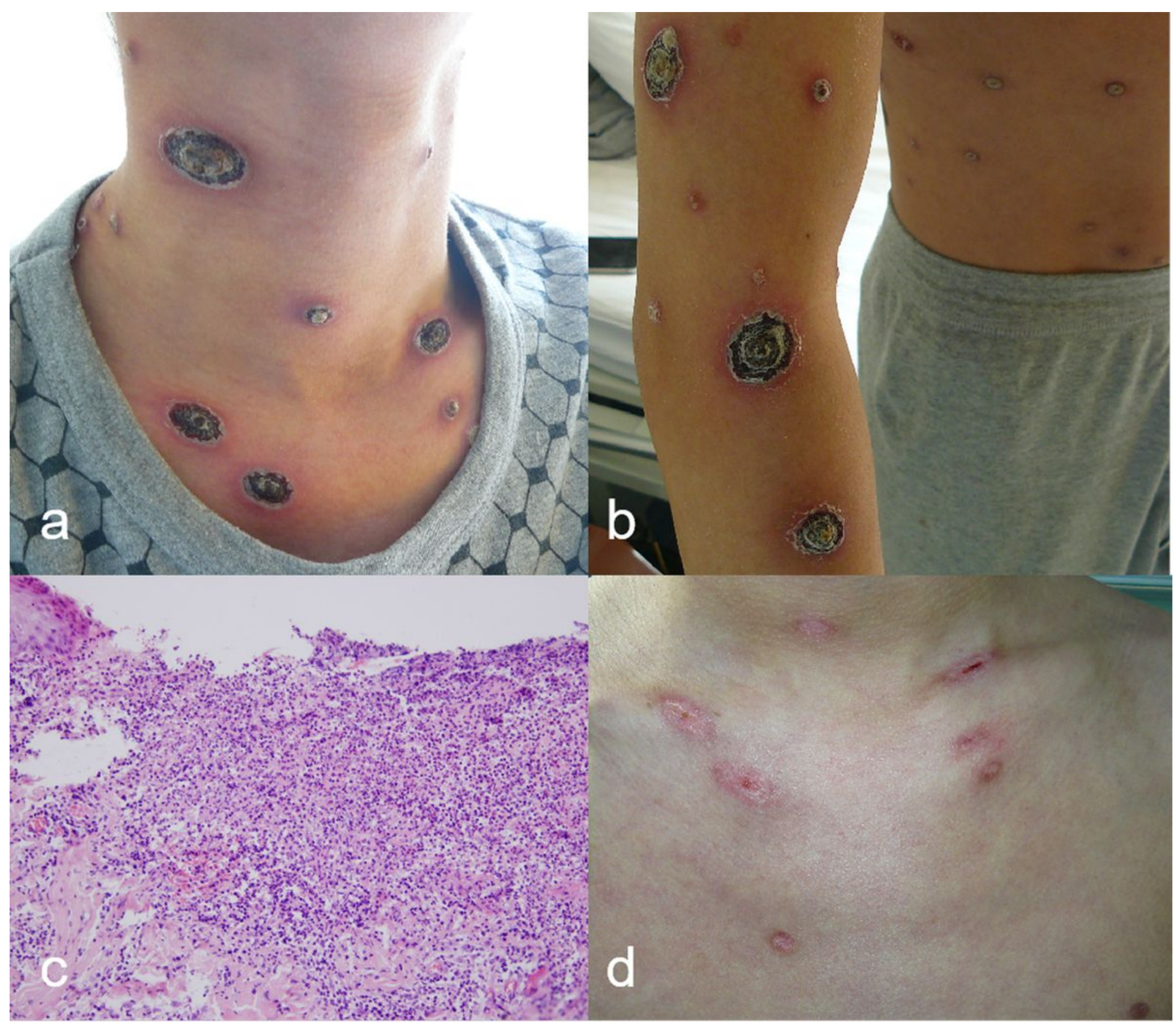

\section{Figure 1}

Multiple skin ulcerations scabbed with overlying brown-black rupioid crusts on the trunk (a) and extremity (b). The biopsy pathology of right forearm lesion (hematoxylin and eosin; original magnification $\times 200)(c)$. There are Scars on the trunk after treatment with benzathine penicillin for 3 weeks (d). 